\section{Ra Ximhai}

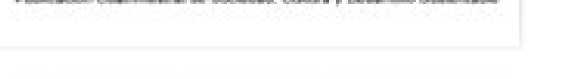

\section{Ra Ximhai}

ISSN: 1665-0441

raximhai@uaim.edu.mx

Universidad Autónoma Indígena de México

México

Sámano-Rentería, Miguel Ángel

Identidad étnica y la relación de los pueblos indígenas con el Estado mexicano

Ra Ximhai, vol. 1, núm. 2, mayo-agosto, 2005, pp. 239-260

Universidad Autónoma Indígena de México

El Fuerte, México

Disponible en: http://www.redalyc.org/articulo.oa?id=46110202

- Cómo citar el artículo

- Número completo

- Más información del artículo

- Página de la revista en redalyc.org

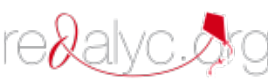

Sistema de Información Científica

Red de Revistas Científicas de América Latina, el Caribe, España y Portugal

Proyecto académico sin fines de lucro, desarrollado bajo la iniciativa de acceso abierto 


\title{
IDENTIDAD ÉTNICA Y LA RELACIÓN DE LOS PUEBLOS INDÍGENAS CON EL ESTADO MEXICANO
}

\section{ETHNIC IDENTITY AND THE RELATIONSHIP BETWEEN THE NATIVE NATIONS AND THE MEXICAN STATE}

\author{
Miguel Ángel Sámano-Rentería \\ Profesor-Investigador. Departamento de Sociología Rural. Universidad Autónoma Chapingo. Chapingo, Estado \\ de México, México. Correo electrónico: asamano@taurus1.chapingo.mx.
}

\section{RESUMEN}

La identidad étnica ha trascendido de una simple diferenciación con los otros a convertirse en una herramienta de lucha etnopolítica, que es utilizada actualmente por los pueblos indígenas de México para relacionarse de una manera diferente con el Estado. Esto implica entender las diferentes relaciones interétnicas que se dan en el entorno nacional y aun mundial, donde la globalización esta provocando paradójicamente que lo local retome fuerza para diferenciarse. Este es el caso de los pueblos indígenas que habían sido sometidos por el régimen liberal durante los siglos XIX y XX y en el nuevo milenio; estos pueblos pretenden liberarse de este sojuzgamiento, identificándose como sujetos sociales con propia voz y luchan por sus derechos con el fin de que se les respete como son, que se reconozca su cultura y sus derechos (consuetudinarios), como primer paso, para después avanzar en la integración de una sociedad multicultural y en la construcción de un Estado pluricultural. En el caso de México se han tenido avances y retrocesos en este sentido, pues actualmente se cuenta dentro de la Constitución Política con el artículo $2^{\circ}$ que reconoce parcialmente la cultura y los derechos de los pueblos indígenas, pero no se ha concretado la elaboración de una ley reglamentaria y a pesar de que el viejo Instituto Nacional Indigenista cambio su nombre al de Comisión Nacional para el Desarrollo de los Pueblos Indígenas, el Estado mexicano sigue practicando una política indigenista de viejo cuño, es decir, de corte asistencialista que no permite tener una relación diferente a la de antes, entre Estado y pueblos indígenas. ¿Cuál es el problema que esta de fondo?. Esto es lo que trata de dilucidar en este trabajo, poniendo sobre la palestra una serie de puntos para su discusión.

Palabras Clave: identidad étnica, multicultural, pluricultural.

\section{SUMMARY}

The ethnic identity has transcended from a simple differentiation with the others to become a tool of ethnopolitical fight being practiced at this time by the Mexico Native Nations to be related with the State in a different way. This involves understanding the different interethnic relationships happening at the national and even world-wide levels, where the globalization is paradoxically causing that the local retake force to differentiate from the others. This it is the case of the native nations that had been dominated by the liberal regime during XIX and XX centuries and in this new millennium these Nations intend to free themselves of this subjugation, identifying themselves as social actors with own voice, and fighting for their rights in order to be respected as they are, recognizing its culture and its rights (consuetudinary), as a first step, for later advancing in the integration of a multicultural society and in the construction of a pluricultural State. In the case of Mexico there have been forward and backward movements in this sense, nowadays there is a law (2nd Art.) within the Political Constitution which partially recognizes the culture and rights of the Native Nations, but at the moment has not materialized into the elaboration of a prescribed law. Furthermore the old Instituto Nacional Indigenista has changed its name for the "National Commission for the Development of the Native Nations", the Mexican State keeps on practicing an indigenous policy of old tradition, that is to say, of social welfare type which does not allow to have a relationship different from the former one, between the State and the Native Nations. What is the problem at the bottom line?. That is what we shall try to explain in this work, putting on the table a series of points for discussion.

Key words: ethnic identity, multicultural, pluricultural.

Recibido: 12 de noviembre de 2004.

Aceptado: 4 de marzo de 2005. 
Identidad étnica y la relación de los pueblos indígenas con el Estado mexicano

\section{INTRODUCCIÓN}

La identidad étnica ha trascendido de una simple diferenciación con los otros a convertirse en una herramienta de lucha etnopolítica, que es utilizada actualmente por los pueblos indígenas de México para relacionarse de una manera diferente con el Estado. Esto implica entender las diferentes relaciones interétnicas que se dan en el entorno nacional y aun mundial, donde la globalización esta provocando paradójicamente que lo local retome fuerza para diferenciarse. Este es el caso de los pueblos indígenas que habían sido sometidos por el régimen liberal durante los siglos XIX y XX y en el nuevo milenio; estos pueblos pretenden liberarse de este sojuzgamiento, identificándose como sujetos sociales con propia voz, y luchan por sus derechos con el fin de que se les respete como son, que se reconozca su cultura y sus derechos (consuetudinarios), como primer paso, para después avanzar en la integración de una sociedad multicultural y en la construcción de un Estado pluricultural.

En el caso de México se han tenido avances y retrocesos en este sentido, pues actualmente se cuenta dentro de la Constitución Política con el artículo $2^{\circ}$ que reconoce parcialmente la cultura y los derechos de los pueblos indígenas, pero no se ha concretado la elaboración de una ley reglamentaria y a pesar de que el viejo Instituto Nacional Indigenista cambio su nombre al de Comisión Nacional para el Desarrollo de los Pueblos Indígenas, el Estado mexicano sigue practicando una política indigenista de viejo cuño, es decir, de corte asistencialista que no permite tener una relación diferente a la de antes, entre Estado y pueblos indígenas. ¿Cuál es el problema que esta de fondo?. Esto es lo que trataremos de dilucidar en esta ponencia, poniendo sobre la palestra una serie de puntos para su discusión.

\section{Los conceptos de identidad y cultura}

Estos dos conceptos a veces se confunden porque están estrechamente interrelacionados. Recientemente se ha procurado hacer una diferenciación para entender el alcance de cada uno de ellos, de manera general podemos decir que el concepto de cultura es más amplio e incluye al de identidad, pero hay diferentes tipos de identidad como la social, la cultural y la étnica, cada una de ellas tiene que ver con las otras y con el concepto de cultura. 
El concepto de cultura es usado en las diferentes ciencias sociales, desde el siglo XIX cuando aparecen la antropología y la sociología como ciencias, pero también ha sido empleada por otras como la psicología y la historia para debatir sobre aspectos que han preocupado a los individuos y a la humanidad. El concepto de cultura puede tener una connotación individual o universal. Actualmente no podemos hablar de una sola cultura sino de una diversidad de culturas existentes en el mundo y dentro de cada país. La obra de Denys Cuche (1999) aborda de manera magistral el desarrollo histórico del concepto de cultura, pero no nos da una definición absoluta de lo que es cultura, sino distintas, en donde hace aportes más particulares es sobre el concepto de identidad, de donde retomaremos algunas ideas que nos parecen centrales. Pero nosotros en este trabajo tenemos que partir de estos dos conceptos básicos que aun hoy están en debate y tomar una posición o mejor dicho adoptar la definición de otros colegas que nos parecen acertadas, para lo que pretendemos abordar en este trabajo.

\section{El concepto de cultura}

Comenzaremos por definir el concepto de cultura que es más amplio y del cual podemos encontrar diferentes definiciones, pero que es un concepto central de la antropología desde que esta nació como disciplina para entender las diferencias entre los pueblos y culturas que habitan los diferentes continentes del mundo. Todo lo que hacemos en la vida cotidiana es una expresión de la cultura. Pero lo que significa para una colectividad o para un individuo es lo que determina su esencia.

Consideramos que una definición de cultura la podemos retomar de Clifford Geertz que plantea lo siguiente:

La cultura se aborda del modo más efectivo continúa esta argumentación, entendida como puro sistema simbólico (la frase que nos atrapa es "en sus propios términos"), aislando los elementos, especificando las relaciones que internas que guardan entre sí esos elementos y luego caracterizando a todo el sistema de alguna manera general, de conformidad con los símbolos centrales alrededor de los cuales se organizó la cultura, con las estructuras subyacentes de que ella es expresión, o con los principios ideológicos en que ella se funda (Geertz,1997).

De esta definición de Geertz, podemos extraer varios elementos esenciales, en primer lugar que la cultura es un sistema simbólico, segundo, que se basa en estructuras culturales, tercero, 
que estas son expresiones de la misma cultura o parten de principios de una ideología ${ }^{1}$, entendida ésta última como cosmovisión.

Esta definición tiene que ver con la concepción de Geertz que trata de ver a la cultura desde la antropología interpretativa, es decir, desde la semiología, que pretende desentrañar el sentido profundo de las cosas, de lo que significan. Pero el mismo Geertz aclara su concepción al proponer dos ideas:

...la primera es la de que la cultura se comprende mejor no como complejo de esquemas concretos de conducta -costumbres, usanzas, tradiciones, conjuntos de hábitos-, como ha ocurrido en general hasta ahora, sino como una serie de mecanismos de control -planes, recetas, formulas, reglas, instrucciones (lo que los ingenieros de computación llaman "programas")- que gobiernan la conducta. La segunda idea es la de que el hombre es precisamente el animal que más depende de esos mecanismos de control extragenéticos, que están fuera de su piel, de esos programas culturales para ordenar su conducta (Geertz, 1997).

Esto que expresa Geertz es importante, porque cada individuo se forja de una manera diferente de acuerdo al ambiente ecológico y social en el cual se desenvuelve, es decir el medio que lo rodea. Para Lourdes Arizpe, es precisamente la cultura lo que diferencia al hombre de la naturaleza, y esto es lo que provoca enfrentamientos entre los pueblos o culturas, porque son diferentes y no permite que se entiendan entre sí (Arizpe, 1989).

Actualmente ante los procesos de globalización, en donde se pretende imponer una cultura homogeneizante surgen y se revitalizan las culturas locales y regionales. El concepto de cultura tiene que ver directamente con otros conceptos analíticos como el de las "creencias" que según Lourdes Arizpe es una categoría primordial de análisis, ya que tendría las siguientes características:

a) se asume sin necesidad de una comprobación filosófica o lógica sino por conformidad; b) el individuo que la asume jamás la pone en tela de juicio; c) para defenderla el individuo repite una argumentación aprendida mecánicamente; d) la creencia tiene la función de proporcionar certidumbre psicológica; e) la reacción frente a un ataque a la creencia es angustia; f) con frecuencia las creencias son tácitas o inconcientes y g) generalmente se trasmiten por signos y son producto de la observación.(Arizpe, 1989).

\footnotetext{
${ }^{1}$ Los subrayados son nuestros
} 
Otro de los conceptos analíticos importantes para Arizpe es el de "valores sociales" que los define así: designa aquellas creencias o ideas que adquieren valor de juicio en una sociedad particular. Los valores sociales son, por tanto, los elementos constitutivos de la ética. Una norma es la formulación de un valor (Arizpe, 1989). Esto tiene que ver con lo dicho anteriormente por Geertz, que son las conductas o programas lo que determinan la forma de actuar de los hombres, es decir, tienen que respetar ciertos valores que les impone la sociedad, el grupo, o su moral propiamente. Lourdes Arizpe señala que: el término de actitudes, parece que es rebasado por la noción de valores y la ética. Se les define como "organización de creencias", cuando a nuestro modo ver bien podian considerarse simplemente como la cristalización de las creencias y los valores en un momento dado...(Arizpe, 1989).

Arizpe (1989) llega a una conclusión que es importante cuando dice: estamos concientes de que estas definiciones de creencias, ideas, ética y valores obligan a establecer modelos esquemáticos, sobre todo tomando en cuenta que participan en un campo simbólico y semiológico que les otorga significados múltiples (Arizpe,1989). La autora citada concluye que para comprender una cultura nosotros tenemos que hacer una interpretación de ésta, como por ejemplo, puede ser la mexicana o cualquier otra y señala:

En síntesis, partimos de la premisa de que la cultura no es un ámbito autónomo de estudio sino un aspecto analítico de los procesos sociales...Si compactamos la historia de los estudios culturales en antropología, podemos superar la premisa de que la cultura esta conformada únicamente por rasgos inconexos, o por el contrario, por un sistema enteramente coherente y unitario (Arizpe, 1989).

Finalmente Arizpe coincide con Clifford Geertz en que es posible hacer "etnografía del pensamiento", aunque esto sea "signos de signos de signos" o la "etnografía de las creencias", pero partiendo de que se entiende por "creencias"(Arizpe, 1989).

Nosotros retomamos aquí la concepción de Lourdes Arizpe y de Geertz porque nos parece que son esenciales sus planteamientos. Si entendemos que la cultura son símbolos o creencias, entonces nosotros tenemos que dilucidar que tipo de símbolos y creencias queremos analizar de una cultura determinada y si nosotros nos referiremos aquí a los pueblos indios de México, tenemos que definir que aspectos, factores o valores tomaremos en cuenta para definirlos. En nuestro caso nosotros nos referiremos a los derechos indígenas, como derechos colectivos que 
tienen que ver con su cosmovisión, con sus creencias y valores que son exclusivos de ellos y estos los diferencian de los demás, por eso tenemos que definir otro concepto que esta muy relacionado con esto y que es el de identidad que lo abordaremos enseguida.

\section{El concepto de identidad}

Al igual que el concepto de cultura el de identidad ha sido discutido desde varios puntos de vista, podemos decir que su origen esta en la psicología social (Cuche, 1999) ${ }^{2}$, pero fue retomado por la antropología y la sociología, ya que tiene que ver con individuos, pero que forman parte de grupos culturales, sociales, o incluso étnicos y de raza. Es un concepto polémico pero necesario como señala Gímenez (2002), de quien nosotros retomaremos ciertos elementos esenciales junto con otros autores que han aportado a definir este concepto complejo, pero a veces se ha simplificado tanto que se ha caído en el manoseo del concepto para aplicarlo indistintamente.

Según Gilberto Gímenez el concepto se podría definir de la siguiente manera:

...la identidad es un conjunto de repertorios culturales interiorizados (representaciones, valores, símbolos), a través de los cuales los actores sociales (individuales y colectivos) demarcan sus fronteras y se distinguen de los demás actores en una situación determinada, todo ello dentro de un espacio históricamente especifico y socialmente estructurado (Gímenez, 2002).

Partiendo de esta definición general el mismo Gímenez retoma algunos parámetros de la problemática de las identidades. En primer lugar señala que identidad y cultura están estrechamente relacionados, ya que la identidad son formas interiorizadas de la cultura, y los actores sociales seleccionan aquellos rasgos culturales que los identifican. En segundo lugar: "la identidad sólo existe en y para sujetos, en y para actores sociales, es decir, relaciones entre los grupos sociales. Por lo tanto no existe identidad en sí ni para sí, sino en relación con “alter"(el otro)". Al respecto agrega Cuche (1999): La identidad remite a una norma de pertenencia, necesariamente consciente porque esta basada en oposiciones simbólicas.

\footnotetext{
${ }^{2}$ El concepto de identidad cultural surgió en los años cincuenta en los Estados Unidos. En ese momento el equipo de investigación de psicología social intentaba encontrar una herramienta adecuada para dar cuenta de los problemas de la integración de los migrantes...(Cuche, 1999).
} 
Por último Gímenez señala que: "la identidad es una construcción social que se realiza en el interior de marcos sociales que determina la posición de los actores y, por lo mismo, orientan sus representaciones y acciones"(Gímenez, 2002).

Además este autor dice que otra característica importante de las identidades, ya sea individuales y colectivas, estas permanecen en el espacio y en el tiempo, aunque sea imaginariamente (Gímenez, 2002). Pero además la identidad es un valor para el sujeto, diferente al que le dan los demás con los que interactúa socialmente y el autor citado llega a la siguiente conclusión:

los actores sociales -sean estos individuales o colectivos- tienden, en primera instancia a valorar positivamente su identidad, lo que tiene por consecuencia estimular su autoestima, la creatividad, el orgullo de pertenencia, la solidaridad grupal, la voluntad de autonomía y la capacidad de resistencia contra la penetración excesiva de elementos exteriores (Gímenez, 2002).

Gímenez (2002) va más allá y define lo que son las identidades étnicas que es lo que nos interesa destacar a nosotros aquí, ya que tiene relación directa con los pueblos indios de nuestro país. Retoma a Fredrik Barth para señalar que: "la identidad que es un producto del proceso de identificación, puede definirse como la organización social de la diferencia cultural". Pero acota que las identidades étnicas son profundamente tradicionales, o sea "sociedades de memoria", pero advierte sobre la confusión que produce la noción de tradición y concluye lo siguiente retomando la definición de Hervieu-Léger: la tradición es el conjunto de representaciones, imágenes, saberes teóricos y prácticos, comportamientos, actitudes, etc, que un grupo o una sociedad acepta en nombre de la continuidad necesaria entre pasado y presente.

Sin embargo Gímenez destaca que las identidades étnicas tienen que ver con territorios no solo físicos donde se reproducen materialmente, sino como un referente simbólico "el territorio sagrado" de la identidad colectiva. Otro elemento importante de la identidad étnica es la lengua, o las variantes dialectales de ésta o lo que llama Gímenez como sociolecto, además señala que este elemento esta ligado a la tradición y a la memoria histórica de los antepasados de comunidad étnica (Gímenez, 2002). 
Según Gímenez (2002), el parentesco y la religión son dimensiones fundamentales de las identidades étnicas, en particular las fiestas patronales son un elemento clave de identidad y resume lo siguiente:

...el sistema religioso tiene por función principalisima la construcción de la identidad étnica. Las imágenes de los abogados y de los santos patronos se hallan insertas en el corazón de los pueblos, presidiendo desde ahi su destino. Son, además, inseparables de las peripecias de su historia, de la memoria de sus antepasados y de sus origenes en el tiempo. A consecuencia de ello, otorgan literalmente identidad a los pueblos, permitiéndoles articular una conciencia de sí.

Del concepto de identidad se deriva otro que es el de la etnicidad, que por su importancia que ha tomado a últimas fechas con el auge del movimiento indígena latinoamericano es importante retomarlo tal y como lo define Aquiles Chihu (2002):

la etnicidad tienen sus fundamentos en los profundos vínculos primordiales de un grupo; es decir, lazos fundados en un territorio común, parentesco y vínculos de sangre, lenguaje, religión, costumbres. A la vez debe tomar en cuenta como este fenómeno sociocultural es usado como instrumento político con el propósito de obtener beneficios para el grupo (Chihu, 2002).

Retomando esta última definición de la etnicidad y retomando lo señalado por Gímenez anteriormente, aclaremos el papel de los tres últimos elementos que son el lenguaje, el parentesco y las costumbres, en particular lo que se refiere al complejo religioso. El lenguaje es un símbolo distintivo de identidad cultural y un código para entender la visión del mundo de una colectividad. El sistema de parentesco es un fundamento de la pertenencia a un grupo y el complejo religioso reafirma la identidad al dramatizar la visión del mundo, de la vida y la muerte. Los miembros de una comunidad se reconocen entre sí y establecen reglas de aceptación y exclusión, y el santo patrón funciona como un símbolo de referencia (Chihu, 2002).

Finalmente hay que tomar en cuenta lo que señala Denys Cuche(2001) cuando dice:

...la diferencia identitaria no es consecuencia directa de la diferencia cultural. Una cultura particular no produce por si misma una identidad diferenciada: ésta solo puede ser el resultado de las interacciones entre grupos y de los procedimientos de diferenciación que instauran en sus relaciones..Esto lleva a considerar la identidad como algo que se construye y se reconstruye constantemente en los intercambios sociales...Dicho de otro modo, identidad y alteridad tienen una parte común y están en una relación dialéctica. La identificación se produce junto con la diferenciación. 
Esto tiene que ver directamente también con el concepto de etnicidad, en donde se da un proceso de identificación y diferenciación con fines organizativos y políticos.

\section{Los pueblos indios de México: como sujetos sociales}

Una cuestión que identifica a los pueblos indios de nuestro país es que tienen diferentes culturas y representan a diferentes etnias, esto hace que México sea un país multicultural y pluriétnico. En el artículo $2^{\circ}$ de la Constitución de los Estados Unidos Mexicanos se reconoce que la Nación mexicana se sustenta en sus pueblos originarios llamados indígenas. Estos pueblos tienen culturas propias, quiere decir, que tienen una cosmovisión y una interpretación simbólica de lo que han sido y son, pero esto también tiene que ver con su derecho practicado tradicionalmente, conocido como es el costumbre o la costumbre.

Entonces un elemento de identidad es su cultura étnica, que se refiere a su lengua, sus tradiciones y sus costumbres, donde la práctica del derecho consuetudinario o no escrito y trasmitido por tradición a través de diferentes generaciones es también un elemento de identidad propia. Pero este derecho consuetudinario o indígena se refiere a un grupo, una comunidad, una colectividad, o una etnia en particular, por lo tanto son derechos colectivos, que de alguna manera mantienen la cohesión del grupo y los diferencia de otros. Cultura y derecho se entrelazan para definir la identidad de estos pueblos indios.

\section{Los derechos de los pueblos indios como elemento de cultura e identidad}

Las autoridades tradicionales representan a sus comunidades y pueblos y dirigen los destinos de su colectividad. Por eso una de las demandas en el reconocimiento de sus derechos y a la autodeterminación, es que se reconozcan a sus autoridades como interlocutores con las instancias gubernamentales y que estas sean reconocidas por los tres niveles de gobierno, a saber, municipales, estatales y federales. La autoridad tiene que velar por los intereses colectivos, el don de mando otorgado por la colectividad en una persona es simbólica, es otorgarle poder para mandar, pero respondiendo a las necesidades de su comunidad o pueblo. 
Una de las luchas que han emprendido los pueblos indios es que se reconozcan sus derechos, y se les reconozca como sujetos sociales o entidades de derecho colectivo. Es decir, lo que piden los pueblos indios es que se reconozcan sus usos y costumbres, representados en sus formas de organización tradicional, que implica el propio sistema de cargos, y las formas de gobernarse y de hacer justicia en el interior de sus comunidades. Esto entra en contradicción con los derechos constitucionales y los derechos humanos, que son considerados como derechos individuales, es decir, se reconocen los derechos civiles del individuo en la constitución, y los derechos humanos pero a cada persona.

$\mathrm{Si}$ a lo anterior le agregamos el no reconocimiento de sus territorios y el ejercicio pleno de su autonomía dentro de su territorio, que como hemos visto, no solo implica el territorio físico sino simbólico, en donde un pueblo se reproduce culturalmente, o sea su hábitat material y espiritual, entonces el reconocimiento de su autonomía a niveles de comunidades, se limita a reconocer la que ejercen de facto y para esto no es necesario su reconocimiento constitucional, además que esta autonomía la reconocerá de manera diferente cada entidad federativa, según se expresa en el artículo segundo de la constitución. No se quiere reconocer el derecho de autonomía de los pueblos indígenas, porque esto implicaría reconocer los derechos colectivos, como lo hemos señalado antes. Si no se reconocen plenamente los derechos de los pueblos tampoco se reconoce su cultura, que es un derecho a su propia identidad.

Si retomamos el concepto de creencias, tratado por Lourdes Arizpe para referirse a las cuestiones religiosas, este lo podemos extender al ámbito del derecho, porque el costumbre, que se ha ejercido por tradición, es un elemento de su identidad y su cultura propia de los pueblos indios. Es decir, no basta con reconocer que existe un sistema religioso basado en una cosmovisión que se podría considerar sincrética, sino que la creencia que el orden y la moral, y por lo tanto los valores, se deben mantener bajo ciertas normas o reglas, aunque no escritas, es un sistema y una forma de convivencia en las comunidades de los pueblos indígenas.

Entonces podemos deducir que el derecho indígena o consuetudinario es un elemento cultural que estas presente en todos los pueblos indios, lo que los diferencia es el ejercicio y las normas que establece cada grupo o pueblo, de lo que es y no es permitido, de acuerdo a sus 
costumbres y su cosmovisión, esto nos lleva al terreno de la identidad diferenciada de cada una de las etnias, o de las culturas. Nosotros tenemos que aprender que dentro de la unidad hay diversidad, y que esta permite la universalidad. Cuando entendamos que somos iguales pero diferentes y que cada uno tiene derecho a ser como es, entonces estaremos avanzando en reconocer y respetar a los demás tal y como son y por lo tanto no debemos empeñarnos en hacerlos a nuestra semejanza para considerarlos como uno de nosotros.

Este dilema de la diversidad cultural y de las diferentes identidades es lo que complica la convivencia en los Estados-nación actuales, que han transitado por la imposición de una cultura dominante nacionalista sobre otras formas de pensar, de ser y de actuar, a una sumisión ante la globalización de una cultura dominante, que tiende a borrar las diferencias nacionales para convertirlas en identidades nacionales subordinadas ante una identidad global homogeneizante. Dicho de otra manera, se quiere eliminar las diferencias culturales construyendo una cultura supranacional que pretende ser supuestamente incluyente, pero que en realidad es excluyente, para aquellos que se niegan a abandonar su propia identidad.

Relacionado con lo anterior, Denys Cuche (1999) dice que la "identidad" se ha convertido en asunto de Estado cuando señala:

El Estado se convirtió en un gerente de la identidad para la cual se instauran reglamentos y controles. En la lógica del modelo del Estado-nación está ser más o menos rígido en materia de identidad. El Estado moderno tiende a la monoidentificación, ya sea porque no reconoce más que una identidad cultural para definir la identidad nacional, ya sea que, aunque admite cierto pluralismo cultural de la nación, define una identidad de referencia, la única verdaderamente legítima. La ideología nacionalista es una ideología de exclusión de las diferentes culturas. Su lógica extrema es la de la "purificación"étnica.

\section{La cultura de los pueblos indios como un derecho}

Una de las reivindicaciones de los pueblos indios es que se reconozca su cultura, es decir, su forma de ser y hacer las cosas, entre éstas esta la defensa de su lengua que es un elemento esencial de la cultura y la identidad de los pueblos. Hasta ahora el Estado ha pretendido por medio de la educación y la enseñanza de la lengua oficial lograr la dominación ideológica de los pueblos, pretendiendo imponer un lenguaje único que atenta contra las lenguas propias de 
los pueblos. Al desaparecer una lengua no sólo se pierde el lenguaje diverso sino se pierde una cultura, una forma de ver el mundo y una forma de expresarse de manera diferente. En este sentido la riqueza cultural de nuestro país se ve diezmada por políticas etnocidas como es pretender erradicar las diferentes lenguas y las formas de pensar.

Otro elemento que es importante retomar es que los pueblos tienen ciertas costumbres y tradiciones que ante los ojos de la cultura occidental no son adecuadas. Es cierto que dentro de las comunidades indígenas la mujer ocupa un lugar secundario en cuanto a participación social y política. Los hombres son los que salen y participan en la mayoría de los casos en asambleas comunitarias y en ellos recaen los cargos que les son designados por la comunidad. La mujer esta a cargo de la casa, de la alimentación y de los hijos, y esto limita la participación de la mujer en muchas actividades sociales y económicas, dentro y fuera de la comunidad. Pero los pueblos, en la medida que tengan un conocimiento más amplio de otras costumbres puede que adopten aquellas que consideren que son adecuadas para ellos. Una de las cuestiones que implica la autonomía es que los pueblos decidan que cambios adoptaran y no se le deben imponer desde fuera.

Una cuestión común para muchos mestizos es que los indígenas son pobres porque quieren, que derrochan dinero en fiestas y ceremonias, y que estos recursos los podrían emplear en otras cosas. El sistema de cargos lo ven como algo que es irracional, desde el punto de vista occidental, ya que alguien que realiza un trabajo o ocupa un cargo debe ser retribuido económicamente. En este sentido lo que nos parece a los mestizos irracional, para los pueblos indios tiene todo una lógica de su reproducción de su cultura, ya que las ceremonias y las fiestas son actos simbólicos, así como el servir a la comunidad es un valor que le da prestigio a aquel que desempaña un cargo.

La introducción de nuevas religiones dentro de las comunidades indígenas ha provocado conflictos, no porque piensen diferentes o profesen otra religión ciertos miembros de la comunidad, sino que las sectas religiosas rompen con la comunalidad y una cosmovisión, al introducir concepciones individualistas que entran en contradicción con las relaciones comunales y esto provoca los conflictos, que han llegado a provocar expulsiones o acciones 
violentas, en donde incluso las instancias gubernamentales tienen que intervenir para tratar de solucionar los conflictos. Lo mismo podemos decir de los partidos, que han partido a las comunidades, por tener ideas políticas diferentes o militar en organizaciones que no son afines. Las diferencias políticas han provocado también conflictos y rompen con la comunalidad, que es parte de su cultura heredada. Los pueblos indios se enfrentan a una serie de problemas inducidos desde fuera de sus comunidades y esto alterando sus formas de ser y de pensar.

Los procesos de aculturación han hecho cambiar a los pueblos indios. La asimilación de ciertos elementos de la cultura occidental están provocando la pérdida de ciertos aspectos de su cultura y de su identidad de estos pueblos. Pero en última instancia será decisión de los pueblos indios que cambios adoptarán y que camino seguirán. Nosotros los de fuera no podemos juzgar a los pueblos indios sobre los cambios que adopten, esto es respetar su cultura como uno de los derechos humanos.

\section{El Estado pluricultural y el derecho de los pueblos indios a la autonomía}

Lo que trataremos en este apartado es sobre la nueva relación que debería establecerse entre los pueblos indígenas y el Estado, partiendo de la reconstitución del actual Estado-nación en otro de carácter plural. Dentro del nuevo Estado los pueblos indios podrían ejercer su autonomía, ¿en qué sentido se entiende ésta y porque no quiere aceptar el actual Estado mexicano el reconocimiento constitucional de esta autonomía y su puesta en práctica?. A esto trataremos de dar respuesta retomando la opinión de otros colegas mexicanos y lo que plantea la UNESCO en cuanto a cultura y desarrollo de los pueblos a nivel mundial.

\section{El Estado plural: la utopía a alcanzar}

Partimos de que los actuales Estados-nacionales se encuentran en crisis debido a factores internos y externos que han determinado una situación de cambio para no desaparecer del todo. Incluso los organismos internacionales como el FMI y el Banco Mundial reconocen que 
los Estados aun tienen mucho que hacer en un mundo globalizado y donde impera el libre mercado, no así el papel de la culturas y las identidades emergentes, que a veces complican el asunto, según esto, debido a la etnicidad:

La etnicidad constituye un factor determinante en la naturaleza y dinámica de los conflictos en aquellas situaciones en que la lengua, la raza o la religión, entre otras características, se usan para diferenciar a los actores que se enfrentan con demasiada frecuencia, el poder de Estado es asumido por un grupo determinado y la construcción del aparato estatal despoja a otros grupos de poder y de influencia. En las situaciones en que el gobierno favorece o discrimina a grupos identificables en términos de etnia, raza o religión, lo que se esta promoviendo es la negociación de privilegios en función de estas identidades, lo cual conduce directamente a la politización de la cultura (UNESCO, 1997)

Pero lo anterior puede tener otra explicación como lo hace Luis Villoro (1998) que parte de la crisis de la soberanía del Estado-nación debido a los cambios externos con la mundialización, que lo debilitan para imponer un sistema político y jurídico en su interior. Luis Villoro (1998) señala:

Muchos Estados nacionales comprenden etnias, culturas y regiones. Tiempo es de reconocer la diversidad y adecuar las divisiones geopolíticas a esa realidad. Pero la pluralidad real de un pais puede ser de varios tipos. La clasificación más general sería la propuesta por Hill Kymlicka, entre "Estados multinacionales" y "Estados poliétnicos". En los primeros, la diversidad "proviene de la incorporación en un Estado de culturas concentradas en un territorio, que tuvieron antes un gobierno propio"; en los segundos "de la inmigración individual y familiar". Algunos países tendrían ambas formas de Estado múltiple.

Pero lo que le preocupa a Villoro es como un Estado unitario puede relacionarse con una diversidad social que caracteriza a México como nación. Además hay que ver cual es la posición del Estado con respecto a las etnias del país, si estas son "minorías" o son "pueblos". Para Villoro (1998):

"Pueblos" pueden ser las naciones (sociedades con una cultura e identidad propias, un proyecto histórico y una relación con un territorio), o bien etnias que tengan su propia cultural, aunque carezcan de la voluntad y el proyecto de ser una entidad histórica distintiva. "Minorías" podríamos llamar, en cambio, a cualquier grupo étnico, racial, religioso o lingüistico, que sea minoritario en su país y no pretenda constituirse en una entidad nacional. Según el derecho internacional vigente, los pueblos tendrían derecho a un estatuto de autonomía, no así las minorías...En suma, la relación, en un Estado plural, entre el poder político y los grupos diversos que componen la sociedad será diferente si se trata de pueblos o de minorías".

Siendo tan importantes estos conceptos de "minorías" y "pueblos" tenemos que recurrir a las definiciones internacionales en este caso retomamos las planteadas en el Informe de la Comisión Mundial de Cultura y Desarrollo de la UNESCO (1997): 
Si bien el término "minorías" ha sido utilizado en diferentes sentidos, el uso internacionalmente aceptado designa con él a grupos marginados o vulnerables que viven a la sombra de poblaciones mayoritarias que tienen una ideología cultural diferente y dominante. Estos grupos comparten sistemas de valores y fuentes de autoestima que en muchos casos derivan de fuentes muy distintas de las culturas mayoritarias.

En el mismo texto antes citado se señalan dos aspectos importantes: 1) en algunos casos los Estados nacionales reconocen a la minorías y establecen normas para reconocer la autonomía de un grupo en base a su territorio y una representación especial ante instancias legislativas y administrativas; y 2) los derechos de las minorías se sitúan entre los derechos colectivos y los individuales, pues aunque son el resultado de pertenencia a un grupo, un individuo puede reivindicarlo como miembro del grupo, "pero estos derechos deben incluir para cada individuo el derecho a separarse voluntariamente de su grupo".

En cuanto a los pueblos indígenas la UNESCO reconoce la definición que da el Convenio 169 de la Organización Internacional del Trabajo relativo a los pueblos indígenas y tribales de los países independientes, que lo define en su artículo $1^{\circ}$.

Para Villoro (1998) un Estado plural tiene que reconocer el derecho a la igualdad pero también a la diferencia, la igualdad no es uniformidad, en lugar de buscar la homogeneidad se trata de respetar por igual las diferencias, por lo tanto un Estado plural tiene que garantizar la equidad a toda minoría étnica, religiosa, racial o sexual. El Estado plural se da en la lucha por una democracia participativa en todos los ámbitos sociales, y agregaríamos nosotros, con la participación de diferentes sujetos sociales y políticos que integran la sociedad y la nación de un país.

Villoro parte de una premisa al señalar: "El Estado de transición hacia un Estado plural supone una tensión. Se basa en la aceptación de una diversidad en la unidad”. Esto es en verdad el gran dilema de la pluralidad hasta que punto se puede mantener la unidad aceptando y reconociendo la diversidad hacia el interior del Estado, además de crear las condiciones necesarias para que pueblos y minorías puedan coexistir, relacionarse y comunicarse. Esto es un proceso que se tiene que ir dando en un Estado de transición hacia un estado plural, donde las diferencias se deben reconocer y tolerar para convivir en la unidad. El Estado plural debe 
propiciar la unidad mediante un proyecto común que trascienda los valores de cada grupo cultural. Las diversas entidades deberían entonces cooperar en un sentido común.

Villoro (1998) concluye lo siguiente con respecto a la utopía posible de Estado plural:

Los distintos grupos mantendrán un sentido de solidaridad en un Estado plural, en la medida en que se respete su identidad y se mantenga una situación tendiente a su trato equitativo frente a otros grupos. En el Estado verían entonces el garante de su posibilidad de cooperar con los otros grupos sin mengua de su particularidad. La principal meta del Estado se vuelve adelantar hacia una meta: la igualdad de oportunidades y la cooperación entre todas las culturas, comunidades e individuos que componen el país. Esa es la equidad. Y la equidad es el signo de justicia.

Con respecto a la identidad de los pueblos en general Luis Villoro (1998) la identifica como una de carácter colectivo y señala puntualmente lo siguiente:

Por identidad de un pueblo podemos entender lo que un sujeto se representa cuando se reconoce o reconoce a otra persona como miembro de ese pueblo. Se trata, pues, de una representación intersujetiva, compartida por una mayoría de miembros de un pueblo, que constituiría un "si mismo" colectivo.

La anterior definición es importante para rebatir a aquellos que niegan que los pueblos tienen una identidad colectiva porque argumentan que es la suma de individualidades las que conforman una sociedad o pueblo y esto lo tratan de ligar con los derechos humanos que supuestamente también son de carácter individual y todo esto para negar los derechos colectivos que reclaman actualmente los pueblos indígenas, como socio-entes colectivos. En este caso es la postura de Rodolfo Vázquez (2001), que pone en el centro del debate esto cuando afirma lo siguiente:

Uno de los debates más serios de fin de siglo, y que ha puesto a prueba los alcances de las diferentes posturas teóricas, y entre ellas, por supuesto, la del liberalismo, es el del multiculturalismo. La crisis que hoy enfrentan los Estados nacionales, por un lado, desde la llamada "globalización" y, por otro, la emergencia de comunidades, los grupos o las etnias culturales, ha obligado a replantear el papel y la importancia de los derechos humanos, especialmente de las minorías, en el marco de los Estados democráticos y sociales de derecho... abordaré esta temática asumiendo explícitamente una defensa de la primacía de los derechos liberales sobre los culturales, en caso de conflicto, y unas reflexiones en torno al valor y los limites de la tolerancia. 
Para Rodolfo Vázquez (2001) es claro que los derechos liberales son individuales al contrario de los culturales que los considera acertadamente como colectivos y considera como conservadores dogmáticos a aquellos que defienden el comunitarismo. Este autor marca su liberalismo, para esto se apoya en teóricos como Sandel, Walter y Kymlicka que se refiere a"lo bueno" como algo sustantivo en la vida de la comunidad o sociedad comunitaria, y dice lo siguiente:

Si los liberales están tan comprometidos con la idea de la imparcialidad del Estado es con el propósito de salvaguardar la autonomía de los individuos. Si el Estado, en respuesta a las demandas comunitarias, es parcial con respecto a ciertos planes de vida, estará asumiendo posiciones paternalistas dificiles de justificar. Por lo tanto reitero que lo importante de entender desde una perspectiva liberal es que la autonomía de los individuos es la condición de posibilidad para la elección y materialización de cualquier plan de vida. El sujeto moral es, desde el punto de vista formativo anterior a cualquier concepción de lo bueno.

Lo que sugiere este autor es que los individuos de una comunidad deben renunciar a su comunidad para poder ser sujetos libres y puedan ejercer sus derechos de manera individual, de ahí la expresión de que si el Estado reconoce demandas comunitarias estaría violando proyectos individuales de vida, que no son compatibles con los de la comunidad. Y el sujeto moral al que se refiere es un individuo cuyos intereses se deben anteponer sobre otros. Al respecto Vázquez dice: “Lo implícito y compartido por todo liberal en esta crítica es la idea de que las entidades colectivas no poseen atributos de individualidad, autonomía y dignidad que caracterizan al agente moral”. Estos también son los argumentos de los legisladores Fernández de Caballos y Manuel Barlett para negar el reconocimiento de los derechos colectivos de los pueblos indígenas, que reclaman con la autonomía.

Para concluir este apartado creo que es importante retomar algunas ideas planteadas en el Informe de la Comisión Mundial de Cultura y Desarrollo de la UNESCO (1997) cuando se señala que:

Promover sociedades pluralistas y resolver conflictos existentes requiere el reconocimiento de la variedad de las estructuras que adquieren legitimidad en diferentes aspectos de la vida social...También es necesario establecer normas que aseguren la protección del ejercicio de los derechos culturales. El poder de persuasión y de aprobación moral de las Naciones Unidas y la opinión pública internacional pueden ejercer una poderosa influencia. A los estados que no traten de discriminar culturalmente a una parte de sus ciudadanos se les podría dar una especie de "aprobación moral" que se negaría a aquellos que practican la discriminación...El objetivo no puede ser simplemente construir una sociedad multicultural, sino un Estado constituido multiculturalmente: 
Identidad étnica y la relación de los pueblos indígenas con el Estado mexicano

un Estado que reconozca la pluralidad sin menoscabo de su integridad. Tal vez sea necesario que ciertas formas de autonomía local, anteriormente proscritas por los Estados fuesen restauradas y garantizadas. No obstante, sigue siendo fundamental la presencia de entidades nacionales(los subrayados son nuestros).

\section{Los pueblos indios y su derecho a la autonomía; pero completa, no parcial}

El filosofo mexicano Luis Villoro (1998) lo plantea clara y contundentemente: El problema indígena solo tiene una solución definitiva: el reconocimiento de la autonomía de los pueblos indios. Este punto de vista nosotros le hemos tratado de sostener en diferentes artículos sobre el problema indígena en nuestro país. Esto es lo que se entiende cuando se habla del cumplimiento de los Acuerdos de San Andrés, que se firmaron el 16 de febrero de 1996 entre el EZLN y el gobierno federal mexicano, a través de la Comisión de Concordia y Pacificación, conformada por los legisladores de los diferentes partidos representados en el Congreso. Sin embargo, como se ha señalado esto no se ha cumplido totalmente sino parcialmente.

Según Villoro (1998) puntualiza que: El Estado moderno nace a la vez del reconocimiento de la autonomía de los individuos y de la represión de las comunidades a las que los individuos pertenecen. Desde su origen lo persigue una paradoja: propicia la emancipación de la persona y violenta los contextos colectivos en que la persona se realiza... Lo expresado por Villoro tiene que ver con dos cosas, desde mi punto de vista esenciales, uno es lo que se refiere al concepto acuñado por Ernesto Garzón Valdés (jurista español) del llamado "coto vedado" y también con la contradicción que hay de los derechos humanos individuales y colectivos. Para unos autores deben prevalecer los derechos individuales sobre los colectivos, pero lo que sugiere el termino de "coto vedado" son un acuerdo tácito entre el Estado y las minorías para respetar ciertos derechos colectivos sin que afecte los derechos individuales de toda la sociedad en su conjunto.

El "coto vedado" no es otra cosa que el núcleo de consenso previo en un convenio de convivencia y asociación libre de sujetos colectivos y minorías con el Estado y otros sectores de la sociedad, que permitan la tolerancia y la construcción del multiculturalismo. Villoro (1998) lo sintetiza así: Es lo que presta unidad a la multiplicidad de sujetos que se asocian libremente. De no aceptarlo, la asociación se romperá”. Pero más adelante el propio Villoro 
apunta una cuestión esencial, que es necesario entender, por que esto tiene que ver con el reconocimiento de los derechos, cuando precisa lo siguiente:

Si el convenio político que da origen a la nación ha de pasar a un convenio impuesto a uno decidido libremente por las partes, tendría que incluir, en el "coto vedado" a toda discusión, el reconocimiento de la autonomía de los sujetos del convenio.

El fundamento del derecho de los pueblos a su autodeterminación es, pues anterior a la constitución del Estado-nación. El orden jurídico no puede fundarlo, solo reconocerlo. La diferencia entre los derechos otorgados y los derechos reconocidos en la constitución de un Estado es importante...la promulgación constitucional se interpreta como una fundación de derechos, cuando no puede ser más que el reconocimiento legal de la libertad de la decisión de los pueblos indios, condición de toda promulgación de sus derechos.

Tenemos que recordar que uno de los derechos fundamentales de los pueblos es el derecho a la autodeterminación, y esto de alguna manera esta explícito en el convenio 169 de la OIT que muchos países latinoamericanos han suscrito, y en el caso de México es ley suprema de acuerdo con el articulo $133^{\circ}$ de la Constitución, pero se argumenta por parte de algunos legisladores y juristas que solo se aplica lo aplicable, porque lo que entra en contradicción con la propia constitución no se aplica, es decir, se aplica parcialmente y solo se refiere al reconocimiento de la existencia de los pueblos indígenas y la multiculturalidad existente en nuestro país. Pero esto no es suficiente, sino se reconocen plenamente todos sus derechos, que implica el derecho a sus territorios a su autodeterminación, en una palabra a su autonomía plena y real como sujetos de derecho, y es aquí donde esta el problema de fondo, el no otorgamiento de estos derechos a los pueblos indígenas de México.

Luis Villoro (1998) critica al liberalismo por su visión individualista de los derechos constitucionales y de los derechos humanos y señala:

Los derechos humanos individuales comprenden el derecho a la autonomía de la persona. Pero las personas no son individuos sin atributos: incluyen la conciencia de la propia identidad como miembros de una colectividad, y esta no puede darse más que en un contexto cultural. Autonomía de una persona es la capacidad de elegir conforme a sus propios fines y valores y de ejercitar esa elección. Y los valores que puede elegir y realizar están, de hecho, delimitados por el marco de una cultura determinada. Las creencias básicas sobre fines y valores sobre valores realizables pueden variar de una cultura a otra (los subrrayados y remarcados son nuestros). 
Para cerrar este apartado debemos relacionar la autonomía de los pueblos indígenas con la construcción del Estado multicultural y nuevamente Villoro (1998) dice:

El fin de las autonomías es garantizar el mantenimiento de la identidad y el desarrollo de los pueblos en el marco de un Estado plural. Las facultades autónomas serán, por lo tanto, las que contribuyan a este fin.

Con esto Villoro señala que es posible construir un dialogo intercultural, que implemente otras cosas el reconocimiento de los territorios indígenas y que los derechos culturales de los pueblos se reconozcan en el jurídico, político y económico, y se debe de cambiar el reconocimiento de los "usos y costumbres" por el reconocimiento de la existencia y vigencia del derecho indígena o consuetudinario. El dilema dice Villoro es como transferir los recursos que son de exclusividad del Estado a las entidades autónomas que se reconozcan, para que se beneficien de los recursos que poseen, y no se siga una política impositivista por parte de las entidades federales, que han creado varios problemas al respecto. Esto es lo que esta de fondo, el no reconocimiento por parte del Estado a la utilización de los recursos de manera autónoma por parte de los pueblos indígenas de nuestro país, de ahí que el dialogo con los zapatistas, entre otras cosas este suspendido.

\section{CONCLUSIONES}

Podemos concluir que el derecho indígena es un elemento de la cultura y la identidad de los pueblos indios de México y por eso consideramos que el Estado-Nación debe reconocerlos plenamente dentro del sistema jurídico mexicano, de esta manera el gobierno y la sociedad haremos explicito el respeto por su cultura. México debe abandonar la idea de que debemos ser una Nación homogénea, al contrario debemos fomentar la pluralidad étnico-cultural y debemos iniciar una campaña de aceptación de los otros como son, entre ellos los pueblos indios de nuestro país. La existencia de estos pueblos es lo que hace de nuestro país una nación rica es su diversidad cultural, la cual no basta con conservarla sino fomentarla y acrecentarla. 
Los no indígenas debemos comprender que la cultura de los pueblos indios es un derecho como el de cualquier hombre, podríamos decir, que es un derecho humano pero colectivo de los pueblos como sujetos sociales. Nosotros debemos mostrar nuestra disposición a reconocer y respetar la cultura de estos pueblos dejándolos ser y permitiéndoles ejercer su autonomía plenamente en todos los aspectos de su vida cotidiana y sus creencias. Nosotros no podemos decir que es bueno y que es malo para los pueblos indígenas. Ellos tendrán que definir su destino.

Los pueblos indios deben ser capaces de resolver sus conflictos, pero también al igual que los mestizos los indígenas deben aprender a ser tolerantes, a aceptar las diferencias incluso dentro de sus comunidades, porque no se pueden mantener al margen del mundo que los rodea. Pero sobre todo ellos tendrían que llegar a resolver estos conflictos internamente, sin la necesidad de que intervengan las autoridades estatales y federales para arreglar estos conflictos, que muchas de las veces derivan en el uso de la fuerza pública o permitiendo que estos conflictos se agudicen, para acusar a los pueblos y comunidades que no son capaces de resolverlos, y con esto justificar la presencia del estado de derecho (o constitucional) sobre los derechos consuetudinarios o el derecho indígena.

Lo que hemos visto a lo largo de este artículo es que es necesario reconocer que la problemática indígena tiene que ver con la construcción de la multiculturalidad y con la construcción de un Estado plural, ante la crisis de los Estados-nacionales golpeados por el neoliberalismo y la llamada globalización. Esta última no llegó para quedarse. Lo que nos muestran las luchas de los pueblos indígenas; entre ellas la de reclamar el reconocimiento de sus derechos en las constituciones federales y estatales (como es en el caso de México), se a convertido en una lucha de carácter etnopolítico, y esto tiene que ver con la etnicidad, o toma de la identidad de los pueblos con identidades colectivas, con derechos colectivos tanto constitucionales como en el terreno de los derechos humanos.

La construcción de una nueva sociedad parte del planteamiento de los pueblos indígenas, para que esta sea incluyente y no excluyente como ha sido hasta ahora. Se trata de practicar la tolerancia y la aceptación de las diferencias en todos los planos sociales (económico, político, 
social, religioso, y cultural) y que esto permita el dialogo de la interculturalidad para crear un "coto vedado" para el nuevo Estado plural a futuro.

\section{LITERATURA CITADA}

Arizpe, L.

1989 "Cultura y Desarrollo. Una etnografía de las creencias de una comunidad mexicana”. UNAM, Colegio de México y Miguel Ángel Porrúa, México. 273 p.

Cuche, D.

1999 "La noción de cultura en las ciencias sociales". Ediciones Nueva Visión, Buenos Aires, Argentina. 367 p.

Chihu, A. A.

2002 "Introducción: Sociología de la Identidad". UAM-Ixtapalapa, Miguel Ángel Porrúa, México. 377 p.

Geertz, C.

1997 “La interpretación de las culturas”. Gedisa editorial, España. 542 p.

Gímenez, G.

2002 "Paradigmas de la identidad". In: Sociología de la Identidad. Aquiles Chihu Amparán coordinador. UAM-Ixtapalapa, Miguel Angel Porrúa, México. 412 p.

\section{UNESCO}

1996 "Nuestra Diversidad Creativa". Informe de la comisión mundial de cultura y desarrollo. Javier Pérez de Cuellar coordinador. Correo de la UNESCO, México. 98 p.

Vázquez, R.

2001 "Liberalismo, Estado de derecho y minorías". Paidós, UNAM-Facultad de Filosofía y Letras, México. 563 p.

Villoro, L.

1998 “Estado plural, pluralidad de culturas". Paidós, UNAM, Facultad de Filosofía y Letras, México. 324 p. 